\title{
1. Introduction to Awaking Europe in the Triple Global Crisis
}

The farther backward you can look, the farther forward you are likely to see.

(Winston Churchill)

\section{THE TRIPLE CRISIS AS A CREATIVE CRISIS: THE INVENTION OF EUROPEAN UNION SOVEREIGNTY}

After decades of over-driven globalization, the triple global crisis has erupted consisting of (1) the socio-economic crisis of the global production system with reinforced inequalities instead of increasing human investment that has become counterproductive in both economic and social respects, (2) the climate crisis by overloading and fatally damaging the human environment, and finally, (3) the recent coronavirus (Covid-19) crisis with its roots in both the over-connectedness by globalization and the structural weaknesses of the public health systems. All three crises have developed their own sub-systems with the internal logic of their workings, and at the same time they have been closely interwoven by forming an interdependent multiple crisis that has reached its final stage in a common and cumulated global crisis. Thus, the basic assumption of this book is that the present world system due to the eruption of the triple crisis has entered the stage of systemic crisis. The cumulated global crisis as the triple - socio-economic, climate and coronavirus - crisis will be briefly outlined at its three - global, European and European Union (EU) regional - levels in this Introduction, and analysed at length in the following chapters. These three levels of crisis have been strictly interlinked on one side and all of them need a special treatment on the other. This analysis has been based on the most recent, innovative literature in European Studies, which has formulated a wake-up call for a change of paradigm to a Re-United, Awaking Europe. ${ }^{1}$

This book tries to argue that within this framework of the recent global crisis the EU27 has gone through a systemic change, as a peaceful 'constitutional revolution', which has brought an essential transformation, leading - in the terms of this book - to both Awaking Europe and Emerging Europe. Awaking Europe is a new Re-United Europe of its big regions (North, South and East). Emerging Europe means upgrading of the EU as a powerful global player in 
the creation of the new multilateral world order with the close partnership of the Wider Europe. This internal-regional and external-global systemic change in Europe does not mean reaching any ideal situation, but it means, indeed, solving some previous vital global problems and forming a qualitatively higher level of the EU polity on its way to federalization/integration. The European management of the triple crisis as the driver of this systemic change with the establishment of EU sovereignty will be explained in various aspects in the following chapters. The systemic crisis started in the last decade by the transformation crisis in the EU that resulted in a regional crisis through the increasingly Fragmented Europe. However, the European systemic change has basically been reached through crisis management of the triple crisis as opening the way for a new kind of development. This itinerary gives the structure of the book. This Introduction offers a general theoretical overview of the conceptual framework on world systems' changes; the second chapter discusses internal EU developments given the rise of Fragmented Europe. Thus, the book proceeds from a general description of the systemic crisis in the EU in the second chapter to a detailed description of the ongoing European systemic change in the third chapter. The specific EU crisis with its deepening Core-Periphery Divide is discussed in the fourth chapter, and the controversial relationship of the EU with the Wider Europe in the fifth chapter. Finally, a short summary of the present situation in the early 2020s is given in the concluding chapter from the perspective of EU systemic change. ${ }^{2}$

In the management of the triple crisis, given the complexity of multidimensional and simultaneous crises, the entire historical trajectory of the EU needs a radical reconceptualization in the early 2020s. The key terms for this reconceptualization are the Awaking Europe as a new quality of the 'internal' EU by 'deepening', and the Emerging Europe as the new size or quantity of the 'external' EU as the global actor with a multi-layered international structure by 'widening'. This process is seen from the historical turning point of the triple global crisis to answer the question whether the 'awaking' and 'united' EU is being able to build an Emerging Europe through further special partnership-type 'enlargements'. It will be an extended EU27+ within a 'globalization cum regionalization' structure by turning to the system of partnerships in Wider Europe and also being ready for an innovative global role in the multilateral New World Order. For a comprehensive discussion of these issues this book makes a long theoretical journey from the recent world system changes through the EU27 general internal developments to the specific transformation processes in Wider Europe. ${ }^{3}$

This new concept of the Awaking Europe and Emerging Europe has been born due to the recent theoretical revolution of European Studies since the beginning of the coronavirus crisis that may be considered as some kind of Enlightenment period in European Studies thanks to the shocking effect of 
the triple crisis has made clear that the old evidences have to be given up. The components of the triple crisis have been running rather separately for a long time, but they have recently merged in an intensive interdependence and produced radical changes of paradigms in all the three related fields: (1) the socio-economic - no fetishization of market economy and especially no repetition of the failed crisis management after the global financial crisis, (2) climate change - no delay in the present urgency phase, which demands the greening of the recent crisis management, (3) the coronavirus crisis - the discovery of the public dimension of health as the crucial issue of social security, with increasing new demands for human investment coming also from the socio-economic crisis. These are the conceptual pillars of this book that will be elaborated through the analysis of Awaking Europe and Emerging Europe. All in all, this is a creative crisis of the EU through a creative destruction of the former structures with an opportunity for a European renewal. ${ }^{4}$

The preconditions of the successful management of the triple global crisis are both the further deepening of the EU in Awaking Europe for its Global Power status in the New World Order and the complex widening process of the Eastern enlargement resulting in the radical renewal of the Europeanization in the Emerging Europe. My former book (Ágh, 2019a) dealt at length with the declining Old World Order (OWO) and the rising New World Order (NWO) since the mid-2010s. This book has engaged in the further treatment of this change in the world systems based on the lessons of the triple crisis. The new federalization wave presupposes both deeper EU integration of the EU27, including overcoming the present Core-Periphery Divide, and the new strategy for the Wider Europe's Europeanization, therefore one of the key points of this book is to explain the historical trajectory of the Europeanization and Democratization. This complex, multilevel process as a nested game is the central interest of this book, seen from the viewpoint of Awaking Europe and Emerging Europe in the NWO in general, and in the triple crisis in particular. ${ }^{5}$

This Introduction proceeds from a short presentation of the triple crisis and the emergence of the NWO through a wider overview of world systems' theory to a reconsideration of EU developments based on this theory. The painful and chaotic transition process between the OWO and NWO began with the management of the global financial crisis, and this process has come to an end when the triple crisis has begun. The coronavirus crisis has indicated that there is no return to the OWO, and the NWO has been organized in a radically different spirit. This new global challenge will turn into a real opportunity to overcome the deep internal contradictions of the galloping globalization, since the basic change from the OWO to NWO is irreversible. The triple crisis as a condensed form of systemic crisis has made evident that the transition between the OWO and NWO has come to an end and the NWO has basically been completed. As pointed out below, the outbreak of the coronavirus crisis 
has pushed the Transatlantic Divide to breaking point. With this process the fight between the multilateralists and the unilateralists has returned at a higher level. Because the outbreak of the coronavirus crisis has brutally uncovered the deep contradictions of the OWO, the triple crisis has made necessary the reconceptualization of world systems' theory, and the related EU, regional and domestic developments in the NWO. Since early 2020 due to the triple crisis there has been a sharp conceptual turn in the European social sciences with the emergence of many new issues and introducing the terms that has also indicated a revolutionary change in the mindset of the populations.

While in the 2010s there was still some ignorance about the counterproductive workings of the global production and trade system and the excessive globalization eroding the world order, in the recent crisis management the rise of the idea of the Awaking and Emerging Europe has been formulated as the sovereignty of the EU. The first reactions to the triple crisis were also threatened by the further slide to the economic nationalism that provoked the spiral of mutual retaliation and 're-nationalization' in the EU. It has turned out, however, that the national snail shells do not work in the pandemic at all. Hence, multilateral cooperation is needed beyond the EU, with more resources from international bodies, such as the World Health Organization (WHO), because the weak national healthcare systems will increase the damage done by new waves of pandemic. The borders cannot be closed any longer for the long term. Instead of 'long-distance globalization' more 're-localization' and/or re-regionalization is needed with enhanced viability and resilience of countries and/or regions themselves, and less dependence on the excessive globalized supply chains or oversized global circulation of production and trade. There is an urgent demand to shorten the supply and production chains to make them sustainable and reliable, including the agreed green conditions in general, and the green landing criteria in particular, to reorganize the severely affected airline and travel industries. The eruption of the coronavirus crisis has revealed that this 'hyper-globalization' - using the terminology of Dani Rodrik (2020) - has to be tamed.

Thus, the new type of crisis management with recognition for the reasons behind the crisis and the design of a new multilateral world order must be outlined briefly in this Introduction in order to prepare its detailed presentation in the following chapters. Sustainable globalization has to be designed in a new multilateral world order, instead of the self-ruining globalization based on outdated industries and services, with a close causal link to the 'polluting trio' of trade, transportation and tourism. This is one of the typical global 'collective action' problems with the empowerment of international bodies and global institutions in a multilateral response to the triple crisis. Nowadays, in the coronavirus crisis, the global allocation of resources with the increasing role of planetary institutions can be a matter of life and death. 
For better or worse, but there is no return to the past anyway. This unprecedented triple or cumulated crisis has manifested the inherent divergence of excessive globalization, and its inner contradictions have proved to be the imminent danger for the future of mankind. It has revealed not only the vulnerability of the poor and fragile states and/or populations around the world, but also that of the Western societies after decades of deindustrialization and exaggerated reliance on global networks of production, services, trade and transport, living in the spirit of high profit-seeking and the fetish of consumerism. Due to the increasingly negative effects of excessive globalization, the coronavirus crisis has drastically revealed the overload of the global socio-economic and ecological systems in the present form of global capitalism.

This kind of globalization is an over-driven process throughout the world across the global chains of production and service, trade and transport, including the tourist industry. These global networks have damaged the environmental system 'outside' and the social system by the human over-connectedness 'inside'. Thus, the starting point in the content analysis of the triple crisis is the globalization of production with its complex social preconditions and consequences in the OWO, including the organization of the regions/countries of the world in order to serve special functions in the socio-economic and political world order. Globalization has reached a saturation point in the early 21 st century with a serious internal crisis of the socio-economic sub-system. Also, the damage done to the natural environment had already appeared in the second half of the 20th century as noticed in scientific circles. But their warnings - although more and more supported through United Nations (UN) bodies - were not able to stop, or even decelerate, the crazy drive of global capital fatally damaging the human environment. Finally, climate change reached a turning point in the 2010s, and this crisis of ecological system was put high on the international agenda as one of the main drivers in the transition between the OWO and NWO. In this situation the third component of the triple crisis has erupted from the excessive over-connectedness in the global village, where the deteriorating human environment has also violated the global system of social hygiene and public health as a whole.

The triple crisis has not only displayed the negative features and the counterproductive character of its sub-systems, but it has also strengthened these negative features and more closely connected them. Therefore, the triple crisis will be discussed in the historical annals as one of the biggest turning points in the history of mankind, since it has expressed the essence of the derailed human development on the Earth. The 'long-distance' global economy is behind the triple crisis, which is a waste of resources and ruins the natural environment, and therefore it is high time to invent a new kind of world economy based on an ecologically sustainable system with proper distancing in the global networks. Beyond the climate disaster, the derailed globalization has caused 
serious social polarization and global vulnerability of societies at both local and international levels. The over-globalized economic world system based on cheap and remote labour at a high ecological price is also a great burden of the past. There has been a basic conflict in the global system between the short-term economic interests of the huge multinationals - acting as loose cannons in the world order damaging the social structures and the human environment - both locally and globally.

\section{THEORETICAL REVOLUTION: THE RECONCEPTUALIZATION OF THE WORLD SYSTEMS' THEORY}

The change of paradigms in the management of the global crises has generated the reconceptualization of the world systems' theory and served as the conceptual background for the rising multilateral world order. Due to the systemic crisis nowadays the world systems' theory is again often discussed in political science and international relations (see for instance Wilkin, 2020). This situation needs not only a description of the current radical changes in the world, but also a serious rethinking of international relations (IR) theory. In recent chaotic years everything is drifting and twisting in the world system, therefore the different concepts and political slogans are whirling around both in IR theory and in public discourse. This book attempts to give a short overview, as a theoretical summary of the world systems' theory against the background of ongoing radical changes in the transition between the OWO and the NWO to prepare the theoretical foundations for the analysis of EU integration. It describes only briefly the historical trajectory of the world systems before 1989 (BWO, Bipolar World Order) and it discusses the OWO only as a prelude to the incoming new cycle of the NWO by contrasting these periods.

The conceptual framework of the world systems' theory has been elaborated in the comprehensive approach of Immanuel Wallerstein in his book The Modern World-System (1976), who followed the theoretical traditions of Karl Polanyi. In the 1980s the world systems' theory - usually based on the concept of the 'long waves' in world history - was one of the main trends in IR theory. George Modelski as an influential author in his book, Long Cycles in World Politics (1987), represented the long waves concept from the side of the US hegemony in the world system. According to the original idea of Wallerstein, the world systems have been the big periods of world history since the 16th century, embracing all social relations in their complexity from the economy to cultural life. Actually, this world history in its proper, narrower meaning, starts only with the 'discovery of the world' in the 16th century, with the direct contacts in the basic social dimensions around the world. The world order, in turn, is the regulation side of the world system, its organization structure, 
in which these comprehensive social relations are involved, and coordinated into, a more or less compact system. Most relationships in a world system are regulated legally, some others only by customs. While the legally regulated fields are relatively stable, the other aspects of this complex system are often changing. Usually, the world systems change every half century; in such a way the collapse of the BWO in 1989 took place two hundred years after the French Revolution in 1789. Within the life cycle of a world system there are two sub-periods with a big turn at the mid-time, and each period goes through stages of emergence, consolidation and decline, in such a way the world order is also changing a lot in these sub-periods. In fact, in the declining world system the existing rules are more and more often violated and/or neglected, so this decline is most evident in the erosion - and finally in the collapse - of its world order. ${ }^{6}$

This Introduction depicts the world systems mostly from the side of the world orders, using these two terms in parallel: mentioning system when it is about the comprehensive system in general, and referring to the order when it is about its concrete, organized and regulated form. Although the basic feature of globalization - syncronity, simultaneity or contemporaneity - has played an increasing role in the world systems, and the discussion of globalization continues through the book, this book cannot engage in the presentation of the general theory of globalization, since it would need a book-size analysis. Actually, based on mainstream efforts in the last years, this book presents a change of the paradigms as the implication of Polanyi's theory for the global system, therefore the reference to the 'Polanyi renaissance' comes back several times.

The two world systems can be described briefly in the contrasting terms of multilateralism, integration, de-securitization and dominance in the OWO and unilateralism, disintegration, securitization and fragmentation in the transition to the emerging NWO. The fight for building up a new kind of multilateralism has recently returned with a vengeance in the world system by the efforts of the EU and China, as the main characters, and with the return of the US under the Biden presidency. Russia, India and Brazil as the much weaker players or supporting casts in the drama will be presented in the next chapter. This gigantic change of the world systems in the 2010s produced an EU transformation crisis in the Juncker Commission when the EU strategy for the NWO was prepared. However, its final elaboration and implementation has been left for the Leyen Commission in the general framework of the triple crisis that has important implications for the deepening and widening policy of the EU and its Core-Periphery Divide as well. The triple crisis in the Periphery is bigger and deeper than it has been perceived in the Core, therefore, without giving up the benign neglect of the specific regional crisis in new member states, it is impossible to lessen the Core-Periphery Divide. 
In the transition between these world systems, at the start of systemic crisis, everything is still obscure, since at its start the decline is already felt, but it is not yet clear whether it is a temporary crisis or the end of the former world system. The contours of the emerging new world system are not yet visible, or it is difficult to identify them, and the new rules are still chaotic. The study of the systemic crisis is a very difficult job using a scientific approach, and it is even more so for the actors at different levels from the states to the citizens. The most difficult issue is the differentiation between the main features of the outgoing and ingoing system to find a new certainty and predictability in this Age of Uncertainty. Sometimes the collapse of a world system is rapid and evident, as was the case of the BWO in 1989, which meant the end of 'the short 20th century'. Usually the transitions take a long time, and they are evident only from looking back afterwards, as is the current case of the emerging NWO after a long, protracted transition in the 2010s from the OWO. However, when looking back to the history of world systems - in the spirit of Churchill's dictum - it is easier to understand and conceptualize the emerging NWO, and the rather chaotic transitional stage of systemic crisis between the OWO and NWO that has come to an end with the coronavirus crisis. In this view of world history, the world systems appear in a systemic approach as compact systems with their major characteristics and the predictability of the world order's rules. Thus, after the emergence of a new world system its main features are well arranged and established, and can be described in a scientific approach. ${ }^{7}$

First, in the world systems all states are structured in the hierarchy of their power position with a hegemon power in the centre, some intermediary megaregions usually in the semi-periphery and the rest in the periphery. Each part of the world system plays a role or serves a particular function in this system through the specific process of regionalization. The domestic social structures have been strictly organized according to these three levels in the world systems' hierarchy. The main players are the big powers, actively shaping the entire system, transforming its megaregions into their dependency with some functions of the hegemonic power that can be seen in great details, e.g. in the British Empire. This functionally organized territorial-geographic structure of the regions/countries appears in geoeconomics and geopolitics, whereas from time to time some regions are in the centre of the worldwide confrontations, say, the Middle East. Second, the world system has basically three types of actors, the political rulers, the socio-cultural elites and the citizens in their social/civic organizations. The political rulers on the top 'rule the world', are very active in the formation of the world order, and they organize major events like the Vienna Congress and Yalta Conference when they make the 'surgery' of the world system. The political rulers are acting in cooperation with their socio-cultural elites on the middle level that gives a sophisticated form to these regulations and maintains their applicability by constantly adjusting them to 
the changing situations. These socio-cultural elites create various worldwide organizations from the church institutions to the sports events. The social cultural, media, scientific, religious and civic - organizations at the bottom, beyond their direct domestic functions, exercise pressure on the above levels in different forms, both as civic institutions and the social movements of citizens. The detailed analysis of these actors, however, is beyond the scope of this book, focusing on the triple crisis in the EU, nevertheless, their short presentation is needed for the description of this present transition from the OWO to the NWO at the various EU levels.

The theory of 'the drifting of continental plates' can be used as a model to describe the world system dynamics with the collisions and 'subductions' of the plates on the world map as the movements and positions of superpowers within the world systems:

BWO: dual division, the Euro-Atlantic plate versus the Eastern plate surrounded by the Third World as the archipelago of megaregions and smaller islands.

OWO: one dominating centre, US hegemony with the separating US and European plates, and marked signs of the emerging bigger islands as megaregions (BRICS).

NWO: increasing drift between the Transatlantic, Pacific and Euro-Asian plates, followed by the triple division of the world system between the EU, US and China with new subductions and emerging multilateral world order.

In the BWO the above outlined world systems' theory was conceived as the Wallerstein paradigm, emphasizing the complexity of the world system in the period of these two confronting superpowers with their interlocking economic, social and political sub-systems. This theory has also elaborated the special character and functions of the megaregions and countries in the hierarchical world system, which have been integrated into the world economy as special parts in the international system of division of labour. The systemic integration from outside has produced a deep social disintegration inside, with the heterogeneity of the internal market, domestic society and forced-upon polity in these global units.

On the contrary, the OWO introduced the Huntington paradigm, focusing on the overwhelming universalism with the ruling principle of victory of liberal democracy and market economy worldwide. Actually, this was a period of increasing global marketization under the banner of global democratization, in which the continental, regional and country specialities were marginalized or forgotten under the ideological dictatorship of the quasi 'triumphant democracy'. However, the principle of dependency with the 'negative externalities' 
has come back with a vengeance through the excessive global marketization in the expansion of the developed economies and it has corroded the fairy tale narrative of global democratization. The excessive global marketization has become counterproductive even in the economic fields and resulted in global ecological disaster. At the same time, it has drastically rearranged the countries of winners and losers, and it has led to the decline of the US role in the world system.

The emerging NWO has produced a new collision and fragmentation of the 'continental plates' instead of the universalism under the US hegemony and it has brought back the deepening confrontations of superpowers in a geopolitically rearranged and reoriented world order. The new world system is based on the over-competing tripartite world - EU, US and China - taking into account both the integration-expansion drive of big actors and the specificity of megaregions in the running/galloping globalization. Earlier, the terms of 'geopolitics' meant external forceful transformation, nowadays it is much more a particular mixture of the external and internal, political and economic, ideological and cultural, soft and hard factors. In this ongoing global reorganization, the ruling principle is that 'regions matter', since in this transitory stage there is a 'challenge of varieties' in the global roles. Accordingly, the hard and soft power has been increasingly combined in the world politics, and the security has become a key term across the new world system. Security in its dynamic meaning is the effort in keeping the social fields concerned sustainable and rebalanced despite their close interactions with the aggressively changing world. This complex security has embraced the new dimensions of both soft and hard security, namely, from the side of information, health and digital etc. security, that appears for instance in the conceptual mixtures like the hybrid war. Thus, the terms 'of security' - and also of '(de)-securitization' - has been one of the most often used expressions in both international and domestic matters for characterizing and regulating the processes in this geopolitical age that will be analysed from the EU side. ${ }^{8}$

In the conceptual framework of world systems' theory, it is possible to forecast the future as the megatrends within a given 'long wave', but very difficult, or almost impossible, to predict them across the different waves. Hence in the early 2020s, after the transitory stage it is already possible to describe the main features of the NWO in the incoming geopolitical age. The biggest mistake of many IR theories is that they still consider the former OWO as evident because they have extended its time horizon from the early 1990s to the remote future. Moreover, some political scientists consider the entire era since the end of WWII as one long period, which is basically an American view with the claim of continuing US hegemony in the present world order. The emerging NWO has usually been a big surprise also in European Studies, deeply disturbing the 
status quo-oriented politicians and their loyal experts. Since we are already in the emerging world system, the main contours of the NWO can be seen.

History does not repeat itself, still the long waves of the world systems show some similarities through some repeated features in the new world systems. Briefly, the BWO had been a confrontative world system based on military security and the dual global civilization of the two hegemonic powers, as a stormy and tense period with deeply embedded, hard power-based geopolitical considerations. Although the erosion of the 'Socialist World System' was a long process, the collapse of its international and national institutions came suddenly in the late 1980s. The dual world system in BWO with two inimical parts was followed with a more relaxed and balanced OWO that was a unified world order, a quasi-multipolar system with less 'military' securitization and more multiculturalism until the mid-2010s. In turn, the transition to the NWO entered as a complex re-securitization with the return of military security in a more sophisticated form, producing sharply conflicting identities across the widening global networks. It has opened again a new stormy period with many deepening tensions that have been characterized sometimes as the new Cold War. Focusing on this change between the 'quiet' OWO and the 'turbulent' emerging NWO, it is clear that the US dominance in the OWO within the global system has been seriously shaken in the transition to the NWO. In a view of the longer historical period, it can be seen that the US hegemony in the world system is over. The main question is how the world order will work under the conditions of the declining US role and how the new global role of the EU will be formulated in the EU, US and China triangle. ${ }^{9}$

It is particularly important to distinguish the systemic change in the world - with its transitory systemic crisis - from the usual short crises because the term of crisis has been largely inflated by both the public discourse and the scientific approach, hence the crisis has been one of the most often used notions in the public and scientific parlance. Still, the systemic crisis of world systems, in the case of the OWO turning to the NWO, is absolutely different from the usual short crises in its size and relevance. The 'there is always some crisis'-type of defensive attitude is dangerous, since it prevents the proper reaction in global politics, although the old technics of crisis management from the OWO have become hopelessly outdated in the NWO. It is common that the deep new crisis phenomena have been bagatellized, taken into the package of 'crisis as usual'. Therefore, the systemic crisis has not been perceived completely, but without its perception the crisis management measures have often been counterproductive by reacting to a former situation and provoking chaos. In the OWO people had a less intensive feeling of losing the security in a well-arranged and predictable system, even if they disliked it, and therefore identified themselves as rational actors in a predictable world. Unlike in the emerging NWO, in which they are just drifting with the new events, and have 
the feeling of not being the actors, but the victims of the changes, although the new crisis management measures are on the rise in the EU with the new Strategic Agenda of Green Europe.

In the BWO with the entry of the world systems' theory in the 1960s there was a heated debate between 'externalists' and 'internalists', and - despite the long series of case studies about the Western expansion worldwide - there was no genuine dialogue between them on the 'internalization' of this external influence, as the penetration or invasion of major powers into the (semi-) peripheries. The OWO brought about a big turning point, since instead of dependency formations the global democratization process was put high on the agenda as the dominant narrative in both the public parlance and social sciences. It is true that this process was analysed more and more in its complexity in the excellent ranking institutes like the V-Dem, still this research in the West did not conclude in the discovery of its fundamental contradiction between democracy and dependency, although for instance the 'marketization' dominated in general over the 'policy Europeanization' that created a dangerous 'imbalance' in the EU (Papadia and Cadamuro, 2020). The EU integration through the West European economic expansion in the 'East' produced a huge experiment in 'Democratization through Europeanization', in which this contradiction began to appear in an accelerated way. Still the discipline of European Studies was flying blind for a long time in the spirit of shallow functionalism with the imagined positive feedbacks as well as with an ideological universalism based on the abstract principle of freedom. However, after the global crisis the deep contradiction between democracy and dependency, development and peripheralization has been increasingly revealed. In the BWO Latin America and in the OWO East-Central Europe has turned out to be the model case for the dependency theory, in the spirit of 'the road to hell is paved with good intentions' (see Chapter 4).

\section{THE TRANSATLANTIC DRIFT AND THE NEW MULTILATERAL WORLD ORDER}

The code to understanding the current change of world system turning from the OWO to the NWO is given by the increasing fight around the world order between the multilateralists and unilateralists. In the declining world systems, there is a 'world disorder', since the 'unilateralists' try to make separate, bilateral deals by violating the general rules. From the mid-2010s it has been striking that the hegemon of the previous world system - the US - has violated the rules set and enforced earlier by itself. Trump hailed Brexit in 2016 and in the following years EU leaders, Merkel and Juncker, already reflected this negative US turn. The deepening family quarrel, leading to the virtual divorce between the EU and the US, began with the clashes between the US and the 
other states at the G7 meetings because of the unpredictability of the US global policy. The turning point was the speech of Angela Merkel (2017) in Munich on 28 May 2017 talking about the 'watershed moment' in the world politics, in which Europe has to take its fate into its own hands. In the Bruegel Report on 'Europe in a New World Order' the leading experts have characterized the new situation that 'the US's relative weight in the global economy has declined. The new US administration seems intent on replacing multilateralism with bilateral deals' (Demertzis et al., 2017: 1). Following these political and expert statements, Thomas Piketty (2018) declared that 2018 was already 'the year of Europe'. ${ }^{10}$

The socio-economic weakening of the US became manifest in the aftermath of the global financial crisis. Seemingly, the US coped with this crisis earlier, whereas the EU was seen more sluggish in its own crisis management. But by the mid-2010s it was already clear that the Anglo-Saxon world was the real loser of the global crisis that was shown by Trump's victory in the US and the Brexit referendum in the UK. Basically, 'unlike his predecessors, Trump rejects the very foundations of the liberal international order as evidenced by his contempt for multilateral organizations, his deep mistrust in US traditional allies, and his unilateralist and transactional view of security and trade alliances'. Therefore, 'The future of transatlantic relations has never been more uncertain than in the Trump era' (Dimitrova, 2020: 1, 6). It has become evident that the US has lost its global competitiveness to a great extent and reacted to the transformation of the world system with its counterproductive, unilateralist defensive moves in global trade, which have widened the gap between the US and the rest of the competitive world. The hegemonic role of the US has evaporated and the temporary power vacuum has indicated for the global audience that the hegemonic US role belonged to the past world order. As a result, according to Paul Krugman (2020), the 'American democracy may be dying'. ${ }^{11}$

This is a marked sign of a declining hegemon in an eroding world system, its actions are counterproductive in the emerging world order in the short run, and it will be severely punished by its accelerating internal decline for the long run. At the same time, the rising actors in the world system - EU and China - have tried to elaborate new rules in the spirit of multilateralism against the destabilizing unilateralism, and have demanded to keep the new rules in order to overcome the systemic crisis. In the global meetings - e.g. Osaka G20 Summit and Munich security conferences - EU leaders openly talked about the transatlantic gap and accused the US under the Trump presidency of creating troubles in world politics by indicating that 'Only multilateralism can save us'. Anne Kruger (2020) has noted that 'President Donald Trump's protectionist policies had disrupted supply chains and ushered in an era of heightened uncertainty ... Trump has shown nothing but contempt for multilateralism.' ${ }^{12}$ 
In the OWO the US ceased to be step by step the centre of gravity, the normative model of the democratic politics and society due to its decreasing developmental capacity as well as the repeated failures of democracy promotion abroad, and later by provoking a global disorder under the Trump leadership. After the global financial crisis, the EU was engaged in the crisis management of its 'polycrisis' under the conditions of the declining US dominance in the global system. The European global activity compared to the US decline was felt already in the second half of 2010s because the EU began to develop a global policy of its own. The US-EU strategic divorce starting in 2017 continued with the US intensifying trade wars with the EU. This confrontative US behaviour finally also undermined the security cooperation within the Western alliance system as was seen already at the Brussels NATO Summit on 11 July 2018 that produced 'a missing security umbrella'. It reached a peak in the G20 Summit in Osaka (28-29 June 2019). The G20 Osaka Declaration discussed the global issues in a rather conciliatory way, since it mentioned the deep debate with the US only in the case of climate change (G20, 2019: 10). This G20 Summit meeting already indicated the entry of the NWO with strong statements on both sides instead of diplomatic niceties, since two camps - the unilateralists, basically the US and Russia, and the multilateralists, first of all the EU and China - confronted each other in the fight for a new rule-based world order. Just as an indication, China entered forcefully into the global arena, and it was running ahead in global competitiveness with the entire advantage and disadvantage of its rapid industrialization and urbanization. Thus, in fact, it will take some generations in China to establish a new balance in human investment and way of life. ${ }^{13}$

The deep clash between the unilateralists and multilateralists - between those states wanting to arrange the issues by bilateral negotiations/confrontations rather aggressively and those states wanting to organize a new multilateral rule-based world order for conflict resolution - became evident for the large public just before the Osaka Summit. It was provoked by an ill-famed interview of Putin given right before this Summit to the Financial Times (2019). In this conflictual situation the best answer - as the active confrontation with these aggressive moves, which intended to hinder the elaboration of the new multilateral, rule-based world order - was given by Donald Tusk, then the President of the European Council and travelling at that time to the G20 Osaka Summit:

Thanks to my jet lag I was able to read the whole interview with President Putin in the Financial Times. I have to say that I strongly disagree with the main argument that liberalism is obsolete. We are here as Europeans also to firmly and univocally defend and promote liberal democracy. Whoever claims that liberal democracy is obsolete, also claims that freedoms are obsolete, that the rule of law is obsolete and that human rights are obsolete. For us in Europe, these are and will remain essential 
and vibrant values. What I find really obsolete are: authoritarianism, personality cults, the rule of oligarchs. Even if sometimes they may seem effective. (Tusk, 2019)

This tough answer of Tusk reflects the spirit of Conclusions of the European Council before the Osaka Summit, openly confronting the US line and by supporting the Paris Agreement in climate change, and also drastically condemning Russia for its aggressive behaviour in the Eastern Europe region, above all in Ukraine. Although the Osaka Summit document avoided any drastic reference to this basic confrontation, the EU indicated the contours of the EU fight with the US and Russia in the NWO in the coming decade. The Conclusions, as the basic EU document contained a strong statement that 'The EU will remain a driving force behind multilateralism and the global rule-based international order, ensuring openness and fairness and the necessary reforms. It will support the UN and key multilateral organizations' (EUCO, 2019a: 10).

The international landscape shows the devaluation of the former complex security capacities of the big global players, the US and Russia, since both are losers, although in absolutely different ways. The US has lost not only its global crisis management capacity, but also its domestic development potential and global competitiveness due to 'the GDP gap' between economic growth and human development that has also created a wide gap between the rising expectations of the US population and its declining well-being. Basically, the US way of life with its shrinking social and human capacities is not competitive globally, which leads to extremist-populist eruptions of the former affluent working class that can be seen in the 2020 presidency elections. In Russia, after the chaos and power vacuum in the 1990s, this revenge of losers has also been felt in the aggressive Russian behaviour in Ukraine and the "near neighbourhood', but their main defeat has been the loss of the development potential after the oil boom period in the domestic background. Despite this return to the old timer 'security policy' by the two big losers, however, there is no BWO again.

Nevertheless, due to the returning past in a new disguise, it is necessary to revoke that the key term to describe the BWO is militarism, in which the armed forces should be used in order to win political and economic advantages in the world politics. The hard power politics goes with the big military establishment and strong military spirit, by subordinating all other interests to those of the military. In the BWO the main actor of militarism was the Soviet Union, and to a great extent also its counterpart, the US. Their military spirit was reduced in the OWO, but it has been reborn in the early NWO very strongly with the logic that hard power matters and the military force is the ultima ratio. As indicated above, in the new situation there have been serious debates about the changing concept of security. In the Bipolar World the security - in its militarized form and with implications for all fields of society - was the basic con- 
ceptual framework of IR theory. With the decline of Russia as a global military power and the rise of the EU as a 'civil' global power, in the multipolar OWO the traditional security approach faded away even in the theoretical considerations. So did geopolitics with its focus on regional studies and specificities because of the homogenization of the free, 'liberal world', with the usual US simplicities of the 'American dream' worldwide. In fact, showing its complete insensitivity to the regional cultural factors, the US Department of Defense in early 2020 discontinued its Minerva program on the social dimensions of the foreign policy behaviour in the world politics.

However, in the 2010s this simplistic approach was questioned more and more in the international scholarship, and in the NWO the refocus of security has been again high on the agenda. International security as a complex issue has become anew the hard core of IR theory, but even its narrowest meaning has further widened to a great extent from the OWO to the NWO because in the NWO it has embraced more and more the technological, psychological, ideological and cyber dimensions of security too. International security has also to be seen in its geopolitical dimension and its regional specificities. The alliance of various states - including their coherence, interrelationships and the internal hierarchy of participating actors - matters in the NWO even more. Thus, the international security system of NATO has proved to be questionable with the declining status of the US. Actually, the volatile, non-transparent and unpredictable US behaviour under the Trump presidency - through the weakening of the Western alliance system and launching a trade war against the EU at critical times during the refugee crisis - was a big security threat for the EU in many ways in this new, complex meaning of security. ${ }^{14}$

Actually, in the OWO the 'Americanization' also took place in the EU in many ways, therefore the increasing conflict between the EU and the US gives a new perspective for the rearrangement of the world order with the drastic 'De-Americanization'. The political democratization and the general economic welfare were - and still are - only empty slogans in the US drive for global democratization seen from the side of naked reality. Although globalization itself has been basically a positive process, due to climate change and the coronavirus pandemic it has still been clear that globalization has been over-driven and it has reached its upper limits. It has been an excessive globalization with over-connectedness through the global production and transport chains and networks, including the huge overload to the global ecosystem. The negative features of the excessive globalization in the OWO, however, were closely connected with the Americanization of the world system in the spirit of the aggressive neoliberalism that became a big burden also in the emerging NWO. While in the EU case there have been some genuine efforts to correct and balance the counterproductive strategy of expansive marketization, the US attitude has still been 'unilaterally' harmful in this respect. The neoliberal 
drive in a somewhat moderate form has also been dominant in the EU, and the softer Europeanized version of neoliberalism has also exerted its harmful effects on EU developments.

The rise of the NWO in the 2010s was already the warning sign in the EU for the necessity of its changing global role and building a new multilateral global system, as it is discussed from different sides in this book. This large literature on the 'global systemic change' was in many ways also the preparation for the triple crisis management, first of all in recognizing the necessity of turning to Political Europe due to the increasing global conflicts. Paradoxically, just the leading economists demanded most energetically a drastic turn to politics, for two interconnected reasons. First, there were some aggressive moves of global powers - above US and China - in the world economy with their combined 'politico-economic' means that threatened the 'economic sovereignty' of the EU and needed proper counter-moves from it. This was described in the theoretical analyses and in the media as some kind of 'economic or trade war', in which the EU partners violated the multilateral regulations and/or used strong state 'interventions' through their economic actions abroad. Second, a new generation entered the EU, having a substantial change in lifestyle and a deep concern for the climate crisis, altogether for many issues, in which the proper legal-political response at both the EU and the member states level was unavoidable.

The formation of the new global role of the EU has taken place in three steps. First, the transformation process of Europe began in the mid-2010s when it was realized that the former global crisis management was false and failed, with all of its negative implications for the workings of the policy triangle. Second, it continued in the late 2010s with the reconsideration of over-globalization for the sake of the EU-centred re-globalization, as building EU sovereignty, that led to the need for the reactivation of the EU global role. Third, the eruption of the triple crisis in the early 2020s has increased the conflicts between the EU regions in the Fragmented Europe that has pushed the EU finally to its renewal through a systemic change after 30 years. This deep turning point in EU history was predicted in great details by the big policy institutes in the late 2010s and it was analysed by them in its socio-economic and ecological dimensions. This prediction was formulated for instance in the following strong statement as an important message from the European Policy Centre (EPC) for the next Commission by indicating the main tasks of the radical transformations:

Europe's future will to a large extent depend on the ability of the European Union - including both its institutions and member states - to counter the sources of fragmentation and polarisation which haunt it. That is why the Union's new leadership should follow a shared Leitmotif aimed at 'Re-uniting EUrope' at both 
the European and the national level - for the sake of current and future generations. (Emmanouilidis, 2018: 20)

\section{THE SPECIFICITY OF THE CRISIS MANAGEMENT IN THE EU AND ITS ITINERARY}

The world is now facing the extended triple crisis, since the pandemic-induced health crisis has rapidly ignited a new chaotic economic crisis in the societies paralysed by the long-term neoliberal austerity policy, resulting also in the rise of populism in the EU. It is clear that - mostly due to the former mismanagement of the global financial crisis - the triple crisis has revealed several problems even in the developed countries, all of which must be solved at the same time. Beyond the often-discussed trends of the reinforced inequalities and the rising precariat, these societies proved to be vulnerable in many other ways that has been discovered by the aggressive neopopulism. It is enough to mention just three main socio-economic contradictions of globalization in the EU countries, which will be revisited in the following chapters: (1) the decomposition and disempowerment of the working population, (2) the increasing fight between the generations, and (3) the public service turning to slippery marshland, including the healthcare crisis.

First, on top of the other self-inflicted wounds there has been a deep fragmentation of society with the new sort of 'employment' or earnings for living. It is more and more difficult to describe that part of the population which is beyond the legally organized world of the regular job contracts, having only some kinds of temporary contracts, since these 'jobless' - non-standard, atypical or 'platform' - workers are in fact not 'unemployed'. In the 'gig economy' the labour market is characterized by various forms of employment with a prevalence of short-term contracts or freelance work as opposed to permanent 'standard' jobs. It is much larger than the self-employed group, being a rapidly increasing part of the worker population. In this permanent jobless world of 'employment', households have been depleted of financial cushions, making it harder to afford basic goods like housing and education in the deep and prolonged crisis situation. In the triple crisis this large part of the population is falling out of the production and health systems at the same time because at the time of the crisis they have been excluded from the institutional framework of both the economic world and public service, healthcare and social support that reveals and enhances the contradictions of the entire system of social security. It demands the reconsideration of the social rights of the population, including social and health protection, since without a proper public health system economic development is slowing down, moreover there is also an imminent danger of further waves of the virus-based pandemic. This danger needs not only the empowerment of the population, but also the recog- 
nition of their natural environment with its inner logic, including the human contacts with the animal world that may be transferring the viruses to human beings.

Second, the triple crisis has sharpened the contradictions between the generations, in some exaggerated approaches it has led to the 'fight of generations'. The underlining process is, of course, that the incoming generations have always been socialized in the given period of the socio-economic system with its political and cultural environment, and they have considered the 'normality' seen from this particular generational message. Every turn from socio-economic well-being to social recession also means different conditions for the established and the incoming generations, especially in the case of big disasters like the present triple crisis. Although it would be an exaggeration to distinguish them as the fully fledged OWO and NWO generations, still in a more nuanced analysis, contours can be drawn among the main groups of the young, the middle and the elderly generations according to the axis of the present world system change. Anyway, the cultural reactions and the political activity of these generations have not only been different, but basically conflicting, first of all, in the new, 'green' generation accusing the elderly generation of causing the ecological disaster, while the old generation has suffered much more from the incoming public health crisis.

Third, the increasing unemployment with austerity measures caused a wide social recession within the EU, in which large masses have been excluded from some basic social services, first of all in healthcare, which has painfully pushed them into a health desert during the coronavirus crisis. Hence, the deprivations in health system have cumulated into the 'care crisis'. Of course, all these negative developments in the new crisis situation have appeared much more in the less developed member states through widening the gap between the more and less developed countries. The erosion of public services with the declining social security or evaporating social justice has produced a special tension, since the poor domestic health systems have been unprepared for the shock of the coronavirus crisis combined with the increasing loss of employment. This situation has shown that the public service system even in the most developed countries has become a sinking and shaky marshland because it is non-reliable, non-transparent, non-predictable and, at the same time, an intensively unequal and increasingly privately founded system.

Altogether, the social security approach is missing even when the domestic public service systems have been seriously shaken, although a new effort already can be seen in the EU for the elaboration of minimal social security in the emergening cases, moving gradually to some kind of inclusive Universal Basic Income for social security in Europe. In the triple crisis the dysfunctions of the vulnerable welfare state have also appeared with many unintended consequences in the congested mega-cities and in the conflicting or diverging 
public policies, including the blurred borders in the healthcare between the public and private services. In this public service marshland, reinforced by the coronavirus crisis first of all civic security is missing for the European citizens for a 'normal' civil life both in the EU and at home. Notably well-being with a solid, predictable and foreseeable free space for public life has deteriorated to walking on springy woodland as a sagging surface, with subsiding or sinking socio-economic conditions. The lack of civic security from the social side can also be exemplified with the whirling situation in employment between the potential or actual mass unemployment for the millions of EU citizens since the early 2020s. The sheer absurdity of the EU 'common' labour market along the lines of the Fragmented Europe has become manifest in the case of the transit - e.g. care and seasonal - workers that have been deeply disturbed by the coronavirus crisis by the closed borders.

All these sharp contradictions have come to the surface in the young generation with their increasing percentage of 'jobless' people, in their deepening confrontations against the other generations and with the large involvement in the ill-defined and poor public services home and abroad, especially as migrants or 'travellers'. The entry of the 'green' generation and the general 'greening' tendency in the last decade with the incoming issue of 'climate justice' has made it clear that the crisis management of the previous global financial crisis after 2008 was not only half-made and unaccomplished, but it was false and reinforced the outdated OWO-type neoliberal mismanagement. The triple crisis as the new global challenge has proven that a new type of crisis management is needed, since it has swept away the old evidence like saving the banks 'too big to fail', and shifting the costs of crisis to the population through austerity measures, which have only deepened the crisis and delayed its solution.

The triple crisis has shown the inherent link between the socio-economic, ecological and health systems from the negative side as the lack of 'social hygiene' as the complex system, in which these processes have turned against each other in a downward spiral. The new crisis management can only be successful by establishing their mutual reinforcement in a positive spiral. In these testing times the new definition of globalization necessitates encompassing the close coherence between the economy, ecology and education. The upward convergence within the population as 'the philosophers' stone' represents this view by underling that 'Governments have multiple goals including economic growth, social inclusion and environmental preservation ... By attaching green conditions when granting state aid and guarantees during the COVID-19 crisis, governments could push companies to accelerate the adoption of low-carbon, circular technologies after the crisis is over, and thus aim for a green recovery' (Schoenmaker, 2020: 1). 
In the EU there were four layers to the perception and discussion of crisis. First, at the level of the all EU transnational institutions; second, prepared and summarized by the big policy institutes like EPC, Centre for European Policy Studies (CEPS), Bruegel and many others - accompanied and supported by the Eurostat and OECD; third, the innovative and provoking papers, essays, and the longer or shorter publications in European Studies and the international media, including the 'blog science' that have often been written by eminent social scientists; and fourth, at the popular level of the mass feelings about the effects of crisis, as the trust of citizens in crisis management and the pressure of population on the EU and domestic policies. The big policy institutes deserve special attention, as their concepts are usually much ahead of the EU decision-making process, they prepare the relevant crisis forecasts with the prediction of the socio-economic and political preconditions for the crisis management measures. The most interesting field, however, is the area of short publications in the blog science literature with brief, strong and well-argued statements. The coronavirus crisis has generated a vivid intellectual life in Europe, and this book has profited a lot from this innovative flow of fresh ideas with a new vocabulary, in both the big policy institutes and the vanguard area of the blog science. The popular feelings in the first and second waves of the triple crisis have been studied and documented in a series of the European Parliament (EP) and Eurobarometer public opinion surveys.

The main message of this new progressive thinking at these four levels is that - instead of chaotic and counterproductive moves of the individual member states and their political elites - there is an urgent need for an extension of the EU competences by a common Europeanized crisis management accompanied by the empowerment of the actors both at the top and bottom. First of all, the empowerment of the transnational EU institutions is needed for their effective and initiative role in the management of the triple crisis and for the extension of EU integration to several other social fields like (public) health security as a common self-defence in the pandemic case, or EU coordination of transport and trade regulations for enabling the constant flow of people, commodities and services. The empowerment of the citizens under the crisis conditions demands the safety that they could exercise their rights in their everyday activities in all four freedoms. During the crisis EU citizens realized deeply and shockingly the unity of the European space, since the permanent disturbances in the three freedoms out of four - free movement of persons, commodities and services - was missing, as a grave factor in their everyday life that disturbed also the normal workings of the society as a whole. To highlight the issue: no new effort for the consolidation can be again through the victory of the neoliberal Economic Europe, since it will produce the prolongation and marginalization of the tensions in Political Europe and worsen- 
ing conditions by the new strict austerity measures in Social Europe that could prevent short-term recovery and long-term renewal.

The triple crisis management has produced a systemic legislation as a legal base of EU systemic change. It is presented shortly in this Introduction as the itinerary of the radical transformation giving the legal frame of this process to be filled with the socio-economic and political content in this book in order to arrive at a general evaluation in the Conclusion. The historical trajectory of these extraordinary, 'revolutionary' times with the change of the paradigms can be reproduced through the major events and EU documents in the crucial year of 2020 as the Timetable of systemic legislation as the Timetable of the major political and policy decisions. It was the 'constitution-making' in EU systemic change, as the systemic legislation by the EU decision-making bodies. Actually, there was already a long history of EU crisis management, as a prehistory of the recent one, first of all after the global financial crisis, which serves both as an experience to be learned and as a drastic failure to avoid. The Maastricht Treaty (1993) and the Lisbon Treaty (2009) have offered some regulations for crisis management, but they have only dealt with the common EU actions in the case of the natural or human-made catastrophes or terrorist attacks. The draft rule of law regulations (EC, 2018b) and the organization of rescEU as the European Civil Protection and Humanitarian Aid Operations, founded in 2017 and further developed in 2019 (see EC, 2019), have also been very helpful in the management of the coronavirus crisis.

While the EU has made large efforts to increase its transnational competencies in economic crisis management, social affairs and healthcare have still remained in the member states' competencies. So, in this respect the EU was in a difficult position at the eruption of the coronavirus crisis in early 2020, but still Leyen organized a unit for coordination of the crisis management's actions in the Commission in March 2020, and this coordination committee had regular meetings under the leadership of Commissioner Janez Lenarčič, the European Emergency Response Coordinator. It was the time when the member states' governments were in big trouble trying to coordinate their chaotic domestic reactions to the unprecedented crisis, and the first video conferences of the European Council were unable to reach a deal in the coordination of the first crisis management moves. In general, in the decision-making mechanism - as the 'trialogue' of the Commission, Council and EP - the novelty in the management of the triple crisis is that the EP has played a big and progressive role by pushing the other institutions towards radical, systemic solutions, and finally the European Council has given the political decision to move.

Despite the strong political battles and the whirling theoretical debates, the year 2020 was the era of the creative crisis and the 'redefinition' of the EU concerning the content and degree of European integration. Because of the shocking effects of the unprecedented crisis in the first half of the year the 
new problems were outlined with some delay, and therefore the rethinking or reconceptualization of the EU started after the discovery of the specific new situation. In fact, the change of paradigms, meaning that the former global crisis management should not be repeated and the internal relationship in the EU policy triangle had to be arranged, as the awakening of the EU, was reached by the end of the first half, but its elaboration and implementation was left for the second half. Again, it has to be emphasized that this systemic change in the EU has not created some kind of 'perfect' or 'ideal' formation, but the breakthrough to a higher level of EU federalization has taken place. In this historical moment the Political Europe has defeated the Economic Europe that basically rearranged the Social Europe too. Even if there is a danger of a short 'reverse wave', it will be at this higher level or within the new frame of this systemic change.

Moreover, in 2020 the EU was overburdened with international conflicts and convulsions in the final scenery of the OWO collapse: the vicissitudes of the Trump presidency, the preparations for a hard Brexit, the foreign policy adventurism of the Russian and Turkish regimes on one side, and with efforts for building the new power structure of the NWO on the OWO ruins, first of all facing the Chinese expansion, penetration and infiltration. The new global role of the EU will be discussed later, but it has also to be mentioned here, since it influenced to a great extent the Timetable of the EU decisions. The European Council and the other Council formations had to deal often with these global/ international suddenly emerging issues. The EP was also regularly preoccupied with them, e.g. with the Belarus mass protests. The EU had to accomplish its own systemic change under pressure of the worsening pandemic 'at home' and the increasingly disturbing global situation 'outside'. The cumulated problems led to the October 2020 stalemate, in which the inherent tensions of the Fragmented Europe came to the surface. Finally, the year 2020 proved to be a gigantic roller coaster ride of up and down movements in the systemic legislation, disturbed from time to time by the crazy drives of the 'frugal North' with its negative ethnical stereotypes about the South and East, the angry and urging demands of the South for financial assistance and the tactical moves of the Eastern autocrats threatening the decisions with veto, if their usual corruption business with EU resources is disturbed.

All in all, the characteristic behaviour of EU institutions and the regions occurred throughout the year. After the more or less chaotic confrontations in the first half-year under the Croatian presidency, in the second half-year the behaviour of the dramatis personae, the main actors of this historical drama radically changed. The Commission had an organizational and the EP a creative/mobilizing role. The fight in the first wave was about the controversial regulations of the national crisis management and the demand for bigger EU solidarity by the biggest losers, Italy and Spain. In the second wave the 
battle lines were much more organized between the South and the East, both representing the past with their narrow-minded interests. Accordingly, in the Council formations these diverging interests were overrepresented, and they opposed or slowed down the compromises, while the EP with a large majority of MEPs pushed for the EU renewal and the Commission was the leading force in compromise-making.

With the political scenery occupied with 'the battle of the EU regions', after the outbreak of the triple crisis the 'industry' of social science has been busy and a huge literature has been written on the contrast between the management of the two global crises. Most of the experts have considered that the main reason for the brutality of the triple crisis is that the former global financial crisis was mismanaged. The big companies following the global financial crisis received unconditional state support in the West, and this mistake should not be repeated, as an Oxford professor, Mariana Mazzucato (2020) has argued. She has pointed out that the mistakes of the post-2008 era have to be avoided, when bailouts allowed corporations to reap even higher profits once the crisis was over, but the EU failed to lay the foundations for a robust and inclusive recovery. The bad news is that in her view the Covid-19 crisis has exacerbated all the problems of the other two - socio-economic and climate - crises, but the good news is, in turn, that one can use the current state of emergency to start building a more inclusive and sustainable green economy. This involves the basic idea that there can only be one common solution for the different aspects of the triple crisis because of convergence and interdependence between these economic, social and political reform processes. Even more, there has been widespread consensus that it is impossible to return to the previous situation as the status quo ante, since the entire world will be different after the coronavirus crisis, and since it catapults the need for a solution to the twin - socio-economic and climate - crises.

Actually, the triple crisis has been provoked by excessive neoliberal globalization. The multinationals - the main actors of the over-globalization in the spirit of neoliberal market fundamentalism - have shifted the financial burden of their harmful ecological workings to the states and communities. An overly 'financialized' business sector has been siphoning value out of the society, rather than shoring up long-run growth by investing in research and development, in both wages and worker training. The crux of the matter is that at the turn of the 20th and 21 st centuries the dominant neoliberal idea of market populism - with its claim for the super efficiency of the unlimited 'free market' both locally and globally - has proved to be a dangerous popular misperception and misconception, obscured by the myth of economic/market efficiency. In fact, the costs of this production system have been transferred to, and loaded on, the other social fields by the influential business oligarchs. It has raised the need for the 'myth busters' in order to debunk these neoliberal 
myths produced by their subservient media and the 'industrialized' scientific forums heavily financed by the multinationals. Due to the drastic effects of the coronavirus crisis as a devastating cyclone, the mainstream social science and public discourse has now reached a turning point with the emerging consensus about the common substance and deep connections between the sub-systems of the triple crisis.

The whole system is shaking, and therefore even the financial elite has increasingly considered that the prevailing policy direction of recent years has to be reversed. Even the Financial Times has published an article, written by the newspaper's editorial board (3 April 2020), with the title 'The virus lays bare the frailty of the social contract', in which they have argued that proposals such as Universal Basic Income and increased wealth taxes have to be considered. The New York Times has also published a similar article with the title 'This is not the time to let the market decide' (15 April 2020). They have realized that the Western leaders learned in the Great Depression and after WWII to suggest collective sacrifice, and nowadays also a social contract has to be offered that benefits everyone (see Pettersson, 2020a). Similarly, Dani Rodrik quotes President Macron by declaring that 'we had already the feeling that the established mode of globalization was coming towards the end of its life', therefore a new 'grammar of multilateralism' has to be elaborated (Rodrik, 2020: 1, 4). Rodrik has also identified the global public goods in the spirit of the triple crisis: 'many aspects of fighting health pandemics have a global public good nature, too. Early warning systems, information collection, development of vaccines and medicines provide benefits to all nations ... These considerations clarify why climate change and public health in particular call for globalising policy.' All in all, he reasserts that 'The climate change and (in many respects at least) public health are obvious global public goods.' Returning to the reference of Macron's standpoint, he underlines that the new global public goods - 'education, health, climate, biodiversity' - are different from the former 'global commons' (Rodrik, 2020: 5, 6).

Hence, to speed up recovery in the spirit of establishing EU sovereignty, EU institutions and the member states' governments have to encourage efforts to strengthen the mutually dependent pillars of social and health protection embedded in the fabric of European societies. Overcoming the coronavirus crisis and preventing/escaping the ensuing global economic crisis is an urgent task by making the EU more crisis-resilient in the global system. It will require a new system of social cohesion with the constant retraining of the population to enhance the human capital and a new wave of solidarity through extended public services. A large scale of engagement with populations is needed for effective crisis management. The cherished principles of neoliberal politics are the optimization of conditions for the financial markets and the strict limitation for social and ecological regulation. The opposite strategy for EU solidarity 
should be prioritizing at least the minimal general welfare for the protection of vulnerable people, since health inequality or deprivation is one of the major hindrances of economic development. The reasonably restricted globalization and the human development-centred green economy are the external and internal pillars of EU sovereignty.

\section{NOTES}

1. This book follows the former volume (Ágh, 2019a, see also 2019b) and deals with EU general developments leading to the triple crisis. It has been based on the theoretical revolution in European Studies with its huge recent literature during the crisis management. Since the eruption of the coronavirus crisis there has been an avalanche of literature on the triple crisis, namely of three kinds: (1) EU official declarations and decisions, (2) longer publications first of all by the big policy institutes, and (3) short analyses and/or essays with marked views in the 'blog science'. This Introduction tries to summarize the mainstream progressive literature and the emerging consensus on the major issues in the recent publications of almost 'library' size. As a technical note, the references are separated into (1) general EU official documents (indicated as e.g. 2020/a,b,c), (2) the Timetable of the EU systemic legislation (indicated as 2020/1, 2,3), and (3) general references of European Studies. In the case of short essays, blogs and papers from the internet, the usual pagination cannot always be implemented.

2. The idea that the EU27 has arrived at a big historical turning point after 30 years of Bipolar World Order and has entered a new historical era has been very markedly represented and explained by Habermas (2020) (see Chapter 3).

3. The chapter on the Wider Europe explains that the usual term of enlargement with full membership may not be applicable for the Wider Europe in the foreseeable future.

4. This general overview of the triple crisis will be dealt in the following chapters in their specific contexts, as an open perspective for Awaking and Emerging Europe. The third chapter will return also to the issue of EU sovereignty based on recent events and publications.

5. The book uses the term Core or the West for the Northern and Southern member states together, and Periphery or East for the new member states (NMS), by adding later the term Periphery-1 to South and Periphery-2 to East.

6. On the world systems' theory, including the long waves, see Ágh (2019a: 10-14). The globalization from the side of the long waves - focusing on Modelski's concept - has been presented at length. In general, the world systems' theory since the 1980s has become the standard part of international relations theory and its university education (see Rock, 2020).

7. This innovative drive in the world systems' literature can be seen, e.g. in Dimitrova (2020), Echle et al. (2018), Hakverdi (2019), Hockenos (2019), Khutkyy and Chase-Dunn (2017), Maurice and Menneteau (2019), Outhwaite and Turner (2017), Wilkin (2020) and Woods (2019). See also the Kondratieff theory of long waves, e.g. in Grinin et al. (2014).

8. The three levels of crisis can be approached through the analysis of the dominant 'security' concepts (see Dahrendorf Forum, 2020; Deubner, 2016; Latoszek et al., 2017; Turcsányi and Vorotnyuk, 2018). 
9. Many publications have recently indicated this declining US role in the world system, first of all referring to the Trump presidency and to the change from the multilateral approach to the bilateral confrontations, see Grevi (2019), Hockenos (2019), Tyler (2018) and Woods (2019). See also Delanty (2017) and Khutkyy and Chase-Dunn (2017).

10. The main turning point in the world order has been declared in the official speeches of Angela Merkel (2017) and Jean-Claude Juncker (2018). The Transatlantic Drift has been finally formulated as 'Westlessness' (Wintour, 2020) at the latest Munich security conference.

11. Exceptionally, even Freedom House has been very critical about the US democracy, the latest global report (Freedom House, 2020a: 8) has indicated the drastic decline of the US democracy to 86th place in 2019 and the failure of global democratization by 'Dropping the Democratic Façade' in many countries (Freedom House, 2020b).

12. The US scholarship has also made a profound diagnosis about the US socio-economic crisis. Jeffry Sachs described 'the GDP gap' between economic growth and well-being in the US already in the early 2010s (WHR, 2012). Levitsky and Ziblatt (2018) also qualified the US political crisis as 'death of American democracy' in the late 2010s.

13. The present chaotic situation with the re-entry of Russia as a challenger in the world system and the rise of China as a new global player cannot be discussed here in detail. See Hakverdi (2019) and Shi Ming (2019).

14. Kopstein (2006) has described the 'Transatlantic Divide over Democracy Promotion', and Wetzel et al. (2015) have overviewed this long debate, while Tyler (2018) has underlined that 'European democracies can teach America'. I have dealt with the deep contrast between the European and American democratization concepts at length in my former papers $(2020 \mathrm{a}, \mathrm{b})$. This book briefly outlines the systemic rivalry in the NWO between the EU and the US in the second and third chapters and indicates the emerging systemic rivalry between the EU and China in the fourth chapter. 